\title{
Splenic Volume: Correlation between Ultrasonogram and Standard CT Measurements
}

\author{
Paul FN ${ }^{1}$, Taher $\mathrm{A}^{2}$, Jahan $\mathrm{M}^{3}$, Roy $\mathrm{SK}^{4}$, Sarker $\mathrm{S}^{5}$, Sultana $\mathrm{S}^{6}$ \\ ${ }^{I}$ Department of Radiology \& Imaging, 250 Beded TB Hospital, Shaymoly, Dhaka, Bangladesh \\ ${ }^{2}$ Department of Radiology \& Imaging, BIRDEM, Dhaka, Bangladesh \\ ${ }^{3}$ Department of Radiology \& Imaging, BIRDEM,Dhaka, Bangladesh \\ ${ }^{4}$ Department of Radiology \& Imaging,SSMC, Dhaka, Bangladesh \\ ${ }^{5}$ Department of Radissology \& Imaging NITOR,Dhaka, Bangladesh \\ ${ }^{6}$ Department of Radiology\& Imaging, Appollo Hospital Ltd, Dhaka, Bangladesh \\ e-mail:pauldrfoni@gmail.com
}

\begin{abstract}
Evaluation of splenic enlargement is important in the diagnosis and management of various diseases including liver disease, lymphoma and other primary or metastatic neoplasm. This cross sectional study was conducted in the Department of Radiology and Imaging in Bangladesh Institute of Research and Rehabilitation in Diabetes, Endocrine and Metabolic Disorders (BIRDEM) from July 2007 to June 2009. The main objective of the study was to find out a more accurate sonographic measurement of splenic volume that well correlate with gold standard computed tomography (CT) volume. A total of 228 subjects were included in the study. All the subjects underwent ultrasound and CT examinations for measurement of splenic volume. The mean splenic volume measured by AVL (average length) was $182.62 \pm 80.28 \mathrm{~cm}^{3}$ (mean \pm SD) with range of $45.61-590.93 \mathrm{~cm} 3$ and by CT scan was $190.18 \pm 77.77 \mathrm{~cm}^{3}$ (mean \pm SD) with range of $46.52-565.81 \mathrm{~cm}^{3}$. Most of the subjects $138(60.5 \%)$ had splenic volume $101-200 \mathrm{~cm}^{3}$. Splenic volume was evaluate by CT findings of 228 cases and expressed in $\mathrm{cm}^{3}$. Sonographic splenic volumes were calculated by using the prolate Ellipsoid method AVL (average length) and also expressed in $\mathrm{cm}^{3}$.The mean difference of splenic volume evaluated by CT and sonography was $7.43 \pm 5.39 \mathrm{~cm}^{3}$ with standard deviation of $5.39 \mathrm{~cm}^{3}$ measured from average length (AVL). The mean difference of splenic volume evaluated by two modalities measured by average length was statistically significant $(p<0.05)$.A significant positive correlation was found between splenic volume evaluated by CT and ultrasonogram by using the Prolate Ellipsoid method AVL $(\mathrm{r}=0.9854, p<0.001)$.
\end{abstract}

\section{Introduction}

Splenomegaly is an important clinical finding and well known manifestation of several diseases that may involve in liver disease, portal hypertension, splenic vein thrombosis, lymphoma, other primary and metastatic neoplastic processes, haematologic entities, infectious and immunologic conditions. ${ }^{1}$ The prevalence of splenomegaly due to different kinds of liver diseases like viral hepatitis, liver cirrhosis and related disease are very common in our country. The various factors known to prevail in Bangladesh related to the high incidence of splenomegaly are inadequate health awareness, environmental pollutiona, poor sanitation, contaminated food and drinks, drug and alcohol abuse, various superstitions about liver and spleen diseases, treatment by traditional healers, and limited screening and health care facilities. Some diseases like chronic malaria, chronic kalazar, tropical spruae, chronic myeloid leukemia, storage disease, typhoid fever affect the spleen which is frequent in the country. ${ }^{2}$

Early determination of spleen size is important in the diagnosis and management of subjects in previously mentioned diseases. On the basis of splenic volume, diagnosis and treatment plan may be changed. $^{3}$ Assessment of spleen size by physical examination is subjective and known to be inaccurate. Splenomegaly may occur in subjects in whom the spleen is not palpable. Study showed that in subjects with sarcoidosis, splenomegaly was present in $57 \%$ of the patients (using sonographic criteria to evaluate size) but only $8 \%$ was clinically palpable. ${ }^{4}$ Therefore, evaluation with radiologic imaging is important. Various radiologic techniques (ultrasonography, nuclear imaging, CT and MRI) have been used to estimate 
organ volumes. Among them, sonography is a quick, simple and relatively inexpensive modality that carries no risk of ionizing radiation. The portability of sonography makes it useful in imaging subjects in the intensive care unit (ICU) and coronary care unit (CCU), who may be too unstable for transport to the imaging place.

Several studies showed that the methods of splenic volume measurement by USG and CT with correlation of their findings with each other. Splenic volume, based on CT scan and splenic size based upon radiologist's impression, clinician's assessment are well correlated. A variety of bias determines and/or affects the radiologist's assessment of liver size but not of splenic size. ${ }^{5}$

Assessment of splenic size, based on subjective parameters or a longitudinal length by ultrasonogram alone, but spleen is an irregularly shaped three dimensional organ that may enlarge at different rates in its various dimensions (length, width and thickness). So, physical examination and imaging using one-dimensional measurement may underestimate the organ size. Multidimensional ultrasonographic measurement is a rapid, reliable and low-cost method for detecting the true spleen size. ${ }^{7}$ This realization promotes to establish a more objective means to confirm the size of the spleen by volume using sonography. A study by Loftus et al on cadavers found a clear linear relationship between a sonographic measurement of splenic length and the actual length, volume and weight as measured at autopsy. ${ }^{8}$

No study has so far been available in the country in the field of evaluation of splenic volume determined by ultrasonographic modality that well correlates with splenic volume measured by helical CT which considered as gold standard. Therefore, this study was designed to find out a sonographic method in the accurate determination of splenic volume for diagnosis and follow-up.

\section{Materials and Methods}

This cross sectional study was carried out from July 2007 to June 2009. The study protocol was approved by the Ethical Review Committee, of the BIRDEM, Dhaka. A total of 234 subjects were consecutively selected having age more than 12 years of both sexes, and those who were advised for both USG and CT. Subjects with difficulty in identification of splenic margin by USG and having motion or breathing artefacts were excluded from the study. Finally, 228 subjects comprising 144 males and 84 females were of 21-83 years age group enlisted in the study. Spleen is a reddish and the largest single mass of lymphoid tissue in the body. Its shape varies from a slightly curved wedge to a 'domed' tetrahedron and has a notched anterior border. It lies just beneath the left half of the diaphragm close to the ninth, tenth, and eleventh ribs. The long axis lies along the shaft of the tenth rib and its lower pole extends forward only as far as the mid-axillary line. The size and weight of the spleen vary with age and between the sexes. In the adult, it is usually $12 \mathrm{~cm}$ long, $7 \mathrm{~cm}$ broad and between 3 and $4 \mathrm{~cm}$ wide.

Informed consent was obtained from each participant. At first, ultrasonography and then CT scan were done on the same day. The researcher himself evaluated the splenic measurements of transabdominal sonography and CT volume measurement with the help of experience technologists, and reviewed by two radiologists without prior knowledge of the interpretations of the other to eliminate bias.

Ultrasonographic examination was performed by Siemens, Antares sonoline and Medison sonoace 8000 live [prime]. All CT studies were obtained by helical CT scanner (Siemens, Somatom Emotion duo). During USG the subjects were placed on right posterior oblique position and scanned during suspended respiration. The spleen size was measured in the sagittal plane in the standard oblique coronal orientation to record the maximal length (in centimeters) of the spleen. The transverse plane, perpendicular to the oblique coronal plane, was then measured to record the transverse width and anteroposterior thickness (in centimeters). The transverse dimension of the spleen was measured as the greatest dimension in the transverse plane, and the width was measured as the shortest distance from the hilum to the outer convexity of the spleen. ${ }^{3}$ In case of CT, volume software on the workstation calculates the total volume by adding the volume estimated from the area to the thickness of the spleen on each image.

Collected data were checked, edited and analysed using SPSS software. To see the difference between the measurements paired $\mathrm{t}$ tests were performed. Correlation between the measurements was also done.

\section{Results}

The mean ML (maximum length) in the study was $10.39 \pm 1.51 \mathrm{~cm}($ mean $\pm S D)$ with range (7.16$14.0) \mathrm{cm}$, the mean CCL (Craniocaudal length) was $4.66 \pm 0.91 \mathrm{~cm}$ (mean $\pm \mathrm{SD}$ ) with range (2.40-7.90) $\mathrm{cm}$, the mean $\mathrm{W}$ (maximum width) was $9.65 \pm 1.39$ $\mathrm{cm}$ (mean $\pm \mathrm{SD})$ with range of $(5.40-14.40) \mathrm{cm}$, the 
mean $\mathrm{T}$ (thickness) was $4.59 \pm 0.72 \mathrm{~cm}$ (mean \pm SD) with range (2.80-6.90) $\mathrm{cm}$ (table I).

Table I: Sonographic splenic measurement of the study subjects $(\mathrm{n}=228)$

\begin{tabular}{llll}
\hline \multicolumn{1}{c}{ USG findings $(\mathrm{cm})$} & \multicolumn{1}{c}{ Mean } & \multicolumn{1}{c}{ \pm SD } & \multicolumn{1}{c}{ Range } \\
\hline ML (Maximum length) & 10.39 & \pm 1.51 & $(7.16-14.0)$ \\
CCL (Craniocaudal length) & 4.66 & \pm 0.91 & $(2.40-7.90)$ \\
W (Maximum width) & 9.65 & \pm 1.39 & $(5.40-14.40)$ \\
T (Thickness) & 4.59 & \pm 0.72 & $(2.80-6.90)$ \\
\hline
\end{tabular}

Table II: Sonographicaly determined splenic volume using the Prolate Ellipsoid method $(\mathrm{n}=228)$

\begin{tabular}{lccl}
\hline $\begin{array}{c}\text { Conventional prolate } \\
\text { ellipsoid }\end{array}$ & Mean & $\pm \mathrm{SD}$ & \multicolumn{1}{c}{ Range } \\
\hline $0.524 \times \mathrm{W} \times \mathrm{T} \times \mathrm{ML}$ & 251.62 & \pm 107.08 & $\left(68.37-807.0 \mathrm{~cm}^{3}\right)$ \\
$0.524 \times \mathrm{W} \times \mathrm{T} \times \mathrm{CCL}$ & 113.65 & \pm 54.76 & $\begin{array}{l}(22.85-374.87 \\
\left.\mathrm{cm}^{3}\right)\end{array}$ \\
$0.524 \times \mathrm{W} \times \mathrm{T} \times \mathrm{AVL}$ & 182.62 & \pm 80.28 & $\begin{array}{l}(45.61-590.93 \\
\left.\mathrm{cm}^{3}\right)\end{array}$ \\
\hline
\end{tabular}

Table III: Comparison of CT and sonographically determined splenic volume $(n=228)$

\begin{tabular}{|c|c|c|c|c|}
\hline & $\begin{array}{c}\text { Difference } \\
\left(\mathrm{cm}^{3}\right)\end{array}$ & $\begin{array}{c}\text { Percent } \\
\text { Difference } \\
(\%)\end{array}$ & $\begin{array}{l} \pm \mathrm{SD} \\
\left(\mathrm{cm}^{3}\right)\end{array}$ & $\begin{array}{c}P \\
\text { value }\end{array}$ \\
\hline $\begin{array}{l}\mathrm{CT} \text { volume }-\mathrm{USG} \\
\text { volume } \\
(0.524 \times \mathrm{W} \times \mathrm{T} \times \mathrm{ML})\end{array}$ & 61.44 & 32.4 & 34.81 & $0.001^{\mathrm{S}}$ \\
\hline $\begin{array}{l}\mathrm{CT} \text { volume-USG } \\
\text { volume } \\
(0.524 \times \mathrm{W} \times \mathrm{T} \times \mathrm{CCL})\end{array}$ & 76.53 & 41.0 & 27.81 & $0.001^{\mathrm{S}}$ \\
\hline $\begin{array}{l}\mathrm{CT} \text { volume-USG } \\
\text { volume } \\
(0.524 \times \mathrm{W} \times \mathrm{T} \times \mathrm{AVL})\end{array}$ & 7.43 & 4.3 & 5.39 & $0.001^{\mathrm{S}}$ \\
\hline
\end{tabular}

Splenic volume was evaluated by CT findings of 228 cases and expressed in $\mathrm{cm}^{3}$. Sonographic splenic volumes were calculated by using the Prolate Ellipsoid Method AVL, ML, CCL, and was also expressed in $\mathrm{cm}^{3}$. Significant positive correlations were found between splenic volume evaluated by $\mathrm{CT}$ and ultrasonogram by using the Prolate Ellipsoid average length (figure1) or maximum length or craniocaudal length.

Correlation between splenic volume evaluated by CT findings with sonographically determined splenic volumes using the Prolate Ellipsoid method according to average length $(\mathrm{n}=228)$

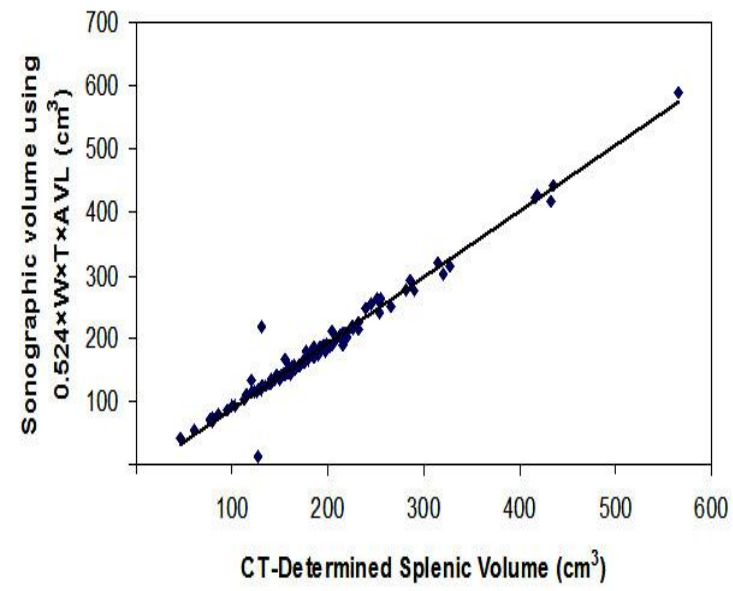

Figure 1: The scatter diagram shows significant relationship $(r=0.9854 \mathrm{~s})$ between splenic volume evaluated by CT findings and Sonographically determined by using the Prolate Ellipsoid Method according to average length

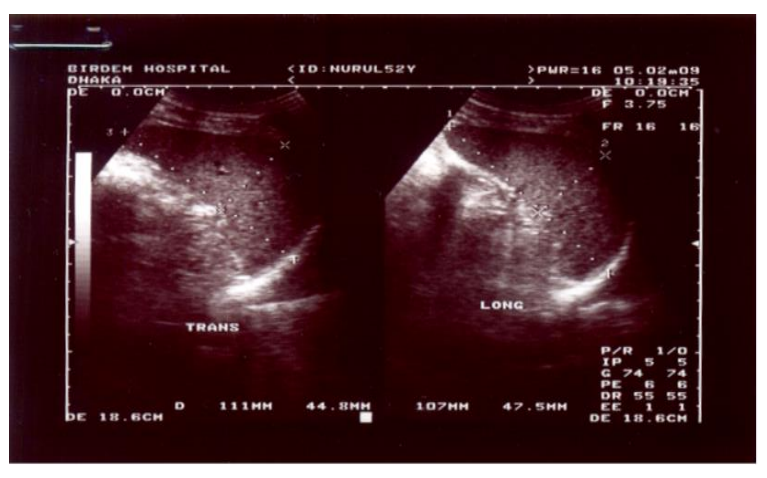

Figure 2:

a) Transverse sonogram illustrates method of determining width and thickness of spleen. Width is measured as greatest overall dimension and thickness is measured as shortest distance between hilum and outer convex surface of spleen.

b) The longitudinal sonogram illustrate method of determine maximum and craniocaudal lengths. Maximum length is measured as greatest overall dimension and craniocaudal length is measured from superior margin to most inferior margin of spleen

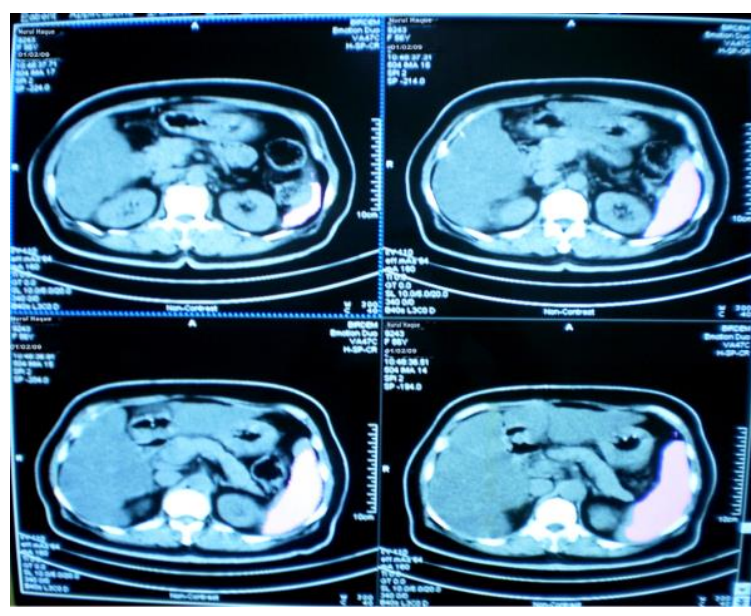

Figure 3: Splenic contossur traced with light pen at CT viewing console

\section{Discussion}

Although gross splenomegaly should be detected clinically, this will not be possible when the enlargement is minor and the spleen is not palpable. Therefore, evaluation by imaging is necessary. Measurement of splenic volume by sonography is the most sensitive method for identifying non palpable splenomegaly. The simplicity and availability has made ultrasonography the primary method of examination of abdominal organs.

There are several formulae to measure the splenic volume by ultrasonography, that correlate well with splenic volume measured by gold standard computed tomography. 
This study was carried out with an objective to find out a more accurate sonographic measurement of splenic volume and to observe the correlation between different sonographic splenic volume measurements with $\mathrm{CT}$ volume.

It was observed that the mean splenic volume was $190.18 \pm 77.77 \mathrm{~cm}^{3} \quad($ mean \pm SD) with splenic volume range of $46.52-565.81 \mathrm{~cm}^{3}$ in CT evaluation. Most of the subjects $(60.5 \%)$ had splenic volume $101-200 \mathrm{~cm}^{3}$. Yetter et alfound the mean splenic volume was $512.6 \pm 349.1 \mathrm{~cm}^{3}$ (mean $\pm \mathrm{SD}$ ) with splenic volume range of 38.6$1448.1 \mathrm{~cm}^{3}$ in CT evaluation, which is higher with the present study, this may due to cirrhotic subjects enrolled in their study. ${ }^{3}$

Odorico et al showed in their series that the mean length was $9.11 \pm 1.24 \mathrm{~cm}$, mean width $9.55 \pm 1.24$ $\mathrm{cm}$, thickness $4.09 \pm 0.79 \mathrm{~cm}$ and ellipsoid splenic volume was $191.54 \pm 71.91 \mathrm{~cm}^{3}$, which is almost consistent with the present study, where the mean ML (maximum length) was $10.39 \pm 1.51 \mathrm{~cm}$ (mean $\pm \mathrm{SD}$ ) with range $(7.16-14.0) \mathrm{cm}$, the mean CCL (craniocaudal length) was $4.66 \pm 0.91 \mathrm{~cm}$ (mean $\pm \mathrm{SD}$ ) with range $(2.40-7.90) \mathrm{cm}$, the mean $\mathrm{W}$ (maximum width) was $9.65 \pm 1.39 \mathrm{~cm} \quad($ mean $\pm \mathrm{SD})$ with range $(5.40-14.40) \mathrm{cm}$, the mean $\mathrm{T}$ (thickness) was $4.59 \pm 0.72 \mathrm{~cm}$ (mean $\pm \mathrm{SD}$ ) with range (2.80-6.90) $\mathrm{cm}$ and the mean splenic volume was $182.74 \pm 80.95 \mathrm{~cm}^{3} \quad($ mean $\pm \mathrm{SD})$ with splenic volume range of (45.61-590.93) cm (using AVL). ${ }^{1}$

The mean splenic volume measured by ML, it was observed that the (mean $\pm \mathrm{SD})$ value was $251.62 \pm 107.08 \mathrm{~cm}^{3}$ with range of $68.37-807.0 \mathrm{~cm}^{3}$, by CCL was $113.65 \pm 54.76 \mathrm{~cm}^{3}$ (mean $\pm \mathrm{SD}$ ) with range of 22.85-374.87 $\mathrm{cm}^{3}$ and by AVL was $182.62 \pm 80.28 \mathrm{~cm}^{3} \quad($ mean \pm SD) with range of $45.61-590.93 \mathrm{~cm}^{3}$. Yetter et al observed that the mean splenic volume measured by maximum length (ML) was $528.7 \pm 314.5 \mathrm{~cm}^{3}$ with range of $68.3-1717.4 \mathrm{~cm}^{3}$, by CCL was $450.8 \pm 302.7 \mathrm{~cm}^{3}$ (mean $\pm \mathrm{SD}$ ) with range of $29.5-1441.2 \mathrm{~cm}^{3}$ and by AVL was $508.1 \pm 312.7 \mathrm{~cm}^{3}$ (mean $\pm \mathrm{SD}$ ) with range of $50.9-1580.5 \mathrm{~cm}^{3}$, which is higher with the present study.This might be due to cirrhotic subjects, but the splenic volume was closely matched with CT measurement, which is consistent with the present study findings. ${ }^{3}$

Mean difference of splenic volume evaluated by CT and sonography was $61.44 \pm 34.81 \mathrm{~cm}^{3}$ measured from ML and the percentage difference was $32.4 \%$. The mean different of splenic volume evaluated by two modalities measured by ML was statistically significant $(p<0.05)$, which is comparable with Yetter et al study, where they found the percentage difference was $10.6 \%{ }^{3}$

Mean difference of splenic volume evaluated by $\mathrm{CT}$ and sonography was $76.53 \pm 27.81$ measured from CCL and the percentage difference was $41.0 \%$. The mean difference of splenic volume evaluated by two modalities measured by CCL was statistically significant $(p<0.05)$, which is also comparable with Yetter et alstudy, where they found the percentage difference was $14.4 \% .^{3}$

Mean difference of splenic volume evaluated by $\mathrm{CT}$ and sonographY was $7.43 \pm 5.39 \mathrm{~cm}^{3}$ measured fromAVL and the percentage difference was $4.3 \%$. The mean different of splenic volume evaluated by two modalities measured by AVL was statistically significant $(p<0.05)$, which is closely resemble with Yetter et al study, where they found the percentage difference was $1.9 \%{ }^{3}$

A significant positive correlation $(r=0.9854$, $p<0.001)$ was found between splenic volume evaluated by CT and uitrasonogram determined by AVL using the prolate Ellipsoid Method, which is a little higher with Yetter et al findings, where they found significant correlation $(r=0.8636$, $p<0.001){ }^{3}$

Similarly, a significant positive correlation but less than AVL correlation $(r=0.8696, p<0.001)$ was found between splenic volume evaluated by CT and ultrasonogram determined by ML. It was also found a significant positive correlation ( $r=0.8640$, $p<0.001$ ) between splenic volume evaluated by CT and ultrasonogram determined by (CCL) which is also less than AVL correlation.

Based on the findings of the study and the findings of other researchers, it is conceivable that sonographically measured splenic volume by average length (AVL) with help of formula 
$0.524 \times \mathrm{W} \times \mathrm{T} \times \mathrm{AVL}(\mathrm{ML}+\mathrm{CCL}) / 2$ is more accurate and correlate well with the splenic volume measured at helical CT.

\section{Conclusion}

Measurement of splenic volume is important than to measure the bipolar length only. Different formulae are used to determine splenic volume at sonogram, among thossse the conventional ellipsoid method using average length (AVL) is the best whicsh correlates well with volume measured by helical CT (considered as gold standard). Thus, this study concludes that the following formula $(0.524 \times \mathrm{W} \times \mathrm{T} \times \mathrm{AVL})$ may be used for evaluation of splenic volume by sonography.

\section{References}

1. Odorico ID, Spaulding KA, Prestorius DH, Lev-Toaff AS, Bailey TB, Nelson TR, et al. Normal splenic volumes estimated using three-dimensional ultrasonography.J Ultrasound Med. 1999; 18: 231-36.

2. Liver foundation of Bangladesh. 1999: available at http://liver.org.bd/

3. Yetter EM, Acosta KB, Olson $\mathrm{MC}$ and Blundell $\mathrm{K}$, Estimating splenic volume: sonographic measurements correlated with helical CT determination.AJR.2003; 181: 1615-20.

4. Spielmann AL, Delong DM and Kliewer MA, Sonographic evaluation of spleen size in tall healthy athletes. AJR.2005; 184: 45-49.

5. Sajjad S, Garcia M, Malik A and Thiel DHV. An assessment of accuracy of hepatic and splenic size based upon a clinician's physical examination, a radiologist's impression and the actual liver and spleen volume calculated by CT scanning, Digestive Diseases and Sciences. 2008;53:1946-50.

6. Lamb PM, Lund A, Kanagasabay RR, Martin A, Webb JAW, Reznek RH, Spleen size: how well do linear ultrasound measurements correlate with three-dimensional CT volume assessments? Brit Inst of Rad. 2002; 75: 573-77.

7. Picardi M, Martinelli V, Ciancia R, Soscia E, Morante R, Sodano A et al. Measurement of spleen volume by ultrasound scanning in subjects with thrombocytosis: a prospective study. Blood. 2002; 99: 4228-30.

8. Loftus WK, Metreweli C. Ultrasound assessment of mild splenomegaly: spleen/kidney ratio. Ped Rad.1998; 28: 98-100. 